\title{
PERBANDINGAN KARAKTERISTIK DAN FUNGSI KATA KETERANGAN BAHASA MANDARIN DAN BAHASA INDONESIA
}

\author{
Yi Ying \\ Chinese Department, Language and Culture Faculty, BINUS University \\ Jl. Kemanggisan Ilir III No 45, Kemanggisan, Jakarta Barat 11480
}

\begin{abstract}
Indonesian is an inflective language or functional language. It is a synthetic language, which is differentiated with agglutinative languages based on the inclination of morphemic formation of words. As a result, segmenting the elements is hard to be done. Mandarin as an isolative language is formed by singular morpheme. Synthetic language as the contrary consists of words of many morphemes. Mandarins' and Indonesian's grammatical function is as adverbs in most of the language occurrences. The difference between two adverbs is that in Mandarin, nouns and numbers cannot receive prefixes and suffixes. Mandarin's adverbs in general are put in the beginning and middle of the words, which is different with Indonesian adverbs that can be placed in the end of the words.
\end{abstract}

Keywords: characteristics, functions, adverbs

\begin{abstract}
ABSTRAK
Bahasa Indonesia merupakan bahasa inflektif atau bahasa fusional adalah jenis bahasa sintetis yang dibedakan dengan bahasa aglutinatif berdasarkan kecenderungan perubahan morfem sewaktu digabungkan dalam pembentukan kata hingga sulit disegmentasi. Bahasa Mandarin merupakan bahasa isolatif adalah bahasa yang kata-katanya terbentuk dari satu morfem tunggal. Lawannya adalah bahasa sintetis yang memiliki kata yang terdiri dari banyak morfem. Fungsi utama gramatikal bahasa Mandarin dan bahasa Indonesia adalah berfungsi sebagai kata keterangan. Perbedaan adverbia kedua bahasa adalah adverbia bahasa Mandarin tidak bisa memodifikasi nomina dan numerial dan tidak bisa ditambahkan awalan dan akhiran. Kedudukan adverba bahasa Mandarin umumnya di awal dan tengah kalimat, sedangkan bahasa Indonesia bisa di belakang kalimat.
\end{abstract}

Kata kunci: kompetensi, penilaian dalam kelas, balikan 


\section{PENDAHULUAN}

Bahasa Mandarin merupakan rumpun bahasa Sino-Tibet, merupakan bahasa yang tidak mengalami perubahan bentuk, bahkan kata kerja dan kata sifatnya juga tidak mengalami perubahan bentuk. Bahasa mandarin mengenal imbuhan yang diletakkan di depan kata kerja dan kata benda. Imbuhan tersebut diletakkan di depan atau di belakang fonem. Misalnya: “阿姨”, “老大”, “小姐” “剪子”, “石头”, “记者”, “扣儿”。

Bahasa Indonesia merupakan rumpun bahasa Austronesia. Dari sudut pandang linguistik, bahasa Indonesia adalah salah satu dari banyak ragam bahasa Melayu. Dasar yang dipakai adalah

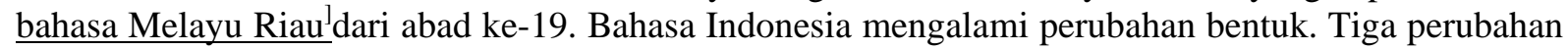
bentuk adalah prefiks, suffiks dan Circumfiks. Misalnya: “sepeda” menjadi "bersepeda”, "rupa menjadi "rupanya, "benar menjadi sebenarnya.

Penelitian tentang tata bahasa Indonesia dimulai sejak tahun 1981. Lapoliwa. H meneliti bunyi dan pelafalan dalam bahasa Indonesia. Pada tahun 1996, James Neil Sneddon meneliti awalan dan akhiran bahasa Indonesia. Rob Goedemans \& Ellen van Zanten meneliti tentang suku kata bahasa Indonesia. Penelitian tentang kata keterangan bahasa Indonesia secara mendalam tidak pernah diadakan sama sekali.

Oleh karena itu, untuk memudahkan mahasiswa dalam membedakan pemakaian kata keterangan bahasa Mandarin dan bahasa Indonesia, maka penulis merasa perlu menulis tentang perbandingan kata keterangan bahasa Indonesia dan bahasa Mandarin. Adapun artikel ini hanya membahas perbandingan karakteristik dan fungsi kata keterangan kedua bahasa. Melalui tulisan ini diharapkan mahasiswa mendapat gambaran perbedaan mendasar kata keterangan kedua bahasa yang bersangkutan dan bisa menggunakannya dalam penyusunan kalimat, khususnya kalimat bahasa Mandarin.

\section{METODE}

Artikel ini disusun berdasarkan studi pustaka, yaitu mencari bahan dari berbagai sumber yang terkait dengan kata kerterangan bahasa Indonesia dan bahasa Mandarin. Sumber informasi diseleksi, dievaluasi, dan dijadikan bahan pendukung artikel ini.

\section{HASIL DAN PEMBAHASAN}

\section{Karakteristik dan Fugsi Adverbia Bahasa Mandarin}

Fungsi utama gramatikal kata keterangan (adverbia) bahasa Mandarin adalah sebagai keterangan, juga memodifikasi ruang lingkup, waktu, derajat, frekuensi, makna positif atau negatif. Adverbia umumnya tidak dapat memodifikasi nomina (frase), kata pembilang (frase), tapi ketika katakata ini berfungsi sebagai predikat, kita dapat menggunakan adverba yang menunjukkan waktu dan ruang lingkup. Adverbia umumnya bebas dari modifikasi kata lain. Adverbia terutama memodifikasi kata kerja, adjektif, atau seluruh kalimat, beserta kata ganti.

Modifikasi kata kerja dan adjektif. Contoh:

事情已经这样了, 光埋怨有什么用?

$$
\text { 好了, 好了, 我知道错了, 别那样了。 }
$$


Adverbia bisa memodifikasi kata ganti yang menggantikan kata kerja dan adjektif, misalnya: 这样,那 样,这么着 dan sebagainya. Contoh:

（3）事情已经这样了, 光埋怨有什么用?

（4）好了, 好了, 我知道错了, 别那样了。

Pada umumnya adverbia tidak dapat memodifikasi verba dan numerial, Contoh:

（5）＊都我们必须去。

（6） * 都我的精力放在希望工程。

Tetapi ketika verba, angka, berfungsi sebagai predikat, maka mungkin menerima beberapa modifikasi adverba yang mennjukkan waktu, lingkup, dan frekuensi. Contoh:

（7）人家都成人了, 别总说人家。

（8）他已经校长了，我才主任，差得也太大了。

(9) 今天报名厦门大学中文系的学生一共两百五十人。

（10） 又星期五了，时间过得可真快呀！

Pada saat kata-verba yang mengandung numerial berfungsi sebagai predikat, maka kata ““就” dan “仅仅” juga muncul dalam di depan predikat, tetapi fungsinya hanya membatasi kualitas. Contoh:

(11）他就一本画报。

（12）我们全组仅仅三个人。

Beberapa adverbia (seperti "tidak", "mungkin", "harus", "agak", "tentu saja" dll) bisa berdiri sendiri untuk menjawab pertanyaan secara individual, mayoritas tidak bisa. Ketika menjawab pertanyaan, adverbia harus bersama-sama dengan lantai diubah predikat datang. Sebagai contoh:

（13）最近没有看到林老师，出差了吗？一也许。（单独回答）

（14）你脸色苍白, 身体不舒服吗? ——有点儿。（同上）

（15）＼cjkstart李录易已经毕业了吗？——已经。 已经毕业了。/是的。

（16） 那儿风景特别美吗? ——*特别。

特别美。/是的。

\section{Karakteristik dan Fungsi Adverbia Bahasa Indonesia}

Fungsi utama gramatikal adverbia bahasa Indonesia juga sebagai kata keterangan. Adverb bahasa Indonesia bisa untuk memodifikasi verba (nomina yang terhitung dan tidak terhitung, beserta verba abstrak), verba, adjektiva, pronomina, numerial, dan frase preposisi. Posisi adjektifa bahasa Indonesia sangat fleksibel, bisa ditempatkan sebelum kalimat, di tengah-tengah kalimat, atau akhir kalimat.

Memodifikasi kata kerja, adjektif, contohnya:

akan datang (将来)

belum bersekolah（还没上学）

sudah gelap（已经天黑）

ingin makan (想吃饭)

masih muda（还年轻）

kurang baik (不太好)

cukup senang (够开心)

jangan duduk (别坐)

lebih tinggi (更高)

sering bercerita（经常讲故事）

Memodifikasi verba, kata pembilang, contohnya:

(1) Seluruh Indonesia mengibarkan Sang Merah Putih.

印: 全印尼 升起 旗 红白

汉: 全印尼升起了红白旗。 
(2) Semua murid harus berkumpul di halaman sekolah.

印: 所有的学生 得 集合 在 园 校。

汉: 所有的学生得在校园集合。

(3) Ada beberapa murid datang terlambat.

印: 有 几个 学生 来 迟

汉: 有些学生迟到了。

(4) Memang ada sejumlah orang tidak setuju dengan peraturan itu.

印: 确实 有一些人不同意于 规定 那

汉：确实有一些人不同意那个规定。

(5) Sebagian uang itu diberikan kepada saya.

印: 一部分 钱 那 被给 对 我

汉：他把一部分钱给我了。

(6) Separuh dari mereka berangkat hari ini.

印: 一部分 从 他们 出发 天今

汉: 他们中的一部分今天出发。

Memodifikasi frasa preposisi, contohnya:

(7) Saya suka menyanyi, tapi hanya di kamar mandi.

印: 我 喜欢 唱歌, 但 只是_在浴室

汉: 我喜欢唱歌, 但只是在浴室里。

(8) Adik suka membaca komik, tapi hanya di kamar tidur.

印: 妹妹喜欢 看 漫画, 但只是在 房间

汉：妹妹喜欢看漫画，但只是在房间里看。

Memodifikasi kata ganti, contohnya:

(9) Saya mau bertemu dengan Beliau saja.

印: 我要见跟他只。

汉: 我只要见他。

(10) Saya mau pergi dengan mereka saja.

印: 我 要 去 跟 他们只

汉: 我只要跟他们一起去。

Kata keterangan Bahasa Indonesia bisa reduplikasi, tambahkan awalan, akhiran dan menambahkan sebelum akhiran.

1. Redulikasi dibagi menjadi tiga:redulikasi kata dasar, reduplikasi kata dasar berakhiran "an”, redupikasi kata dasar berawalan "se".

（1） Reduplikasi kata dasar seperti moga-moga（希望）, malam-malam（很晚）, jarangjarang（很少）, kadang-kadang（偶尔）, kira-kira（大概）, sering-sering（经常）, lagi-lagi（又）, mula-mula（初次）,tiba-tiba（突然）, erat-erat（紧紧）, pelan-pelan (慢慢)

(2) Reduplikasi kata dasar berakhiranan "an” mudah-mudahan (希望), gelap-gelapan（没有公开; 秘密）, mati-matian（拼命）

(3) Reduplikasi kata dasar berawalan "se”. Kata dasar dan awalan "se” atau penggunaan awala "se”dan akhiran "nya” secara bersamaan. Contoh: sepandai-pandai （无论有多聪 明）, sebaik-baiknya（尽力）.

2. Penambahan awalan “di” dan “se”, misalnya: dilarang（禁止）, semoga（希望）, sesekali（偶 尔）,separuh (一半) ,sejumlah（一部分）, sebagian（一部分） 
3. Penambahan akhirannya “nya”, misalnya: kiranya (希望), rasanya (看来), agaknya (看来 ),rupanya (看来) , hendaknya（希望; 应该）. Penambahan awalan “se” dan akhiran "nya”, misalnya: sebaiknya（最好）, sebenarnya（事实上）

Tabel 1 Perbandingan karakteristik dan fungsi adverdia bahasa Indonesia dan bahasa Mandarin

\begin{tabular}{|c|c|c|c|}
\hline & Bahasa Mandarin & & Bahasa Indonesia \\
\hline 1 & $\begin{array}{l}\text { Modifikasi kata kerja, kata sifat } \\
\text { 李雪晶常常去老人院。 } \\
\text { 我很高兴认识你。 }\end{array}$ & 1 & $\begin{array}{l}\text { Modifikasi kata benda, kata kerja, kata sifat, } \\
\text { preposisi, numerial dan frase preposisi } \\
\text { Lin Xuejing sering pergi ke panti jompo（动词） } \\
\text { Saya sangat senang berkenalan denganmu（形容词） } \\
\text { Kami mau bertemu dengan Beliau saja.（代词） } \\
\text { Dia merokok hampir lima bungkus sehari（数量词） } \\
\text { Saya suka menyanyi hanya di kamar mandi. (介词短语) }\end{array}$ \\
\hline 2 & $\begin{array}{l}\text { Adverbia bisa diletakkan di awal dan } \\
\text { tengah kalimat. } \\
\text { 难道你不想参加期末考试吗? } \\
\text { 这几道问题大家回答得都很好。 }\end{array}$ & 2 & $\begin{array}{l}\text { Bisa diletakkan dia awal, tengah dan akhir kalimat. } \\
\text { Kelihatannya dia tidak menyetujui usul itu. } \\
\text { Melihat penampilannya, dia pasti seorang guru. } \\
\text { Ayah tidak mendukung rencana kita tampaknya. }\end{array}$ \\
\hline 3 & $\begin{array}{l}\text { Sebagian kecil adverbia bisa berdiri sendiri } \\
\text { untuk menjawab pertanyaan. } \\
\text { 他们知不知道这件事情? 不。 } \\
\text { 你手头里有没有钱? 没有。 } \\
\text { 他会同意我们的计划吗?一定。 } \\
\text { 听到那件消息, 她难过吗? 有点儿。 }\end{array}$ & 3 & $\begin{array}{l}\text { Hanya adverbia positif dan negatif yang bisa berdiri sendiri unruk } \\
\text { menjawab pertanyaan } \\
\text { Apakah mereka mengetahui hal ini?Tidak. } \\
\text { Apakah kamu sudah mebayar uang sewa kamar?Belum. } \\
\text { Apakah dia dapat menepati janjinya?Tentu. }\end{array}$ \\
\hline 4 & 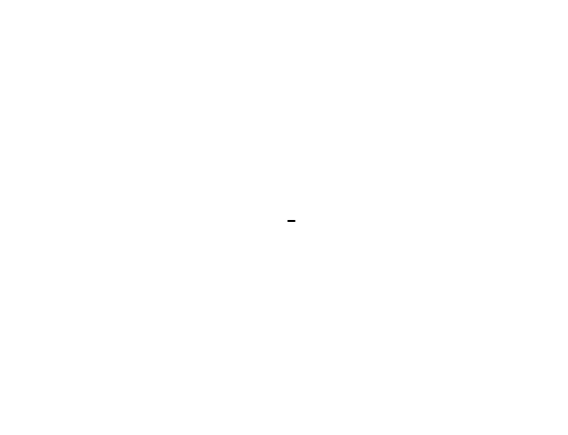 & 4 & $\begin{array}{l}\text { Bisa reduplikasi } \\
\text { Reduplikasi kata dasar, misalnya: } \\
\text { tiba(到/V) menjadi tiba-tiba（突然/Adv）, diam（安静/Adj） } \\
\text { menjadi diam-diam（偷偷摸摸/Adv） } \\
\text { Reduplikasi kata dasar diambah akhiran “an” } \\
\text { 形容词mudah（容易/Adj）+后缀“an”,按续成mudah-mudahan（ } \\
\text { 希望/Adv） } \\
\text { mati (去世/动词) +后缀“an”, 按续成mati-matian（拼命/Adv） } \\
\text { 。例如: } \\
\text { Mereka mati-matian melawan musuh. } \\
\text { (他们拼命地抵抗敌人) }\end{array}$ \\
\hline 5 & - & 5 & $\begin{array}{l}\text { Kata dasar + awalan“se” } \\
\text { pandai (聪明) +前缀“an”, 按续成sepandai-pandai（无论有多 } \\
\text { 聪明）。例如: } \\
\text { Sepandai-pandai orang, ada kalanya dia salah (keliru) juga. } \\
\text { (一个人无论有多聪明, 他也会犯错误) }\end{array}$ \\
\hline 6 & - & 6 & $\begin{array}{l}\text { Kata dasar + kata depan “di” } \\
\text { larang (不允许/V）+前缀“di”, 按续成dilarang（禁止，表示被 } \\
\text { 动意义的动词）。例如: } \\
\text { Dilarang merokok. (禁止吸烟) }\end{array}$ \\
\hline 7 & - & 7 & $\begin{array}{l}\text { Kata dasar ditambah akhiran “nya” } \\
\text { kira (猜) +后缀“nya”, 按续成kiranya（希望; 看来/Adv）例 } \\
\text { 如: } \\
\text { Kiranya Anda dapat memaklumi keadaan saya. } \\
\text { (希望你能理解我的情况) } \\
\text { rasa（味道; 感觉/noun）+后缀“nya”，按续成rasanya（看来） } \\
\text { Rasanya saya mengenal wanita itu. } \\
\text { (看来我认识那位女人) }\end{array}$ \\
\hline 8 & - & 8 & $\begin{array}{l}\text { Penambahan awalan “se” dan akhiran “nya” } \\
\text { dalam (深) +前缀“se”+后缀, 按续成sedalam-dalamnya（深厚 } \\
\text { ，真的）例如: } \\
\text { Kami mengucapkan bela sengkawa sedalam-dalamnya. } \\
\text { (我们表示深厚地哀悼） }\end{array}$ \\
\hline
\end{tabular}




\section{PENUTUP}

Dari perbandingan karakteristik dan fungsi bahasa Mandarin dan bahasa Indonesia diperoleh simpulan, yaitu: (1) adverbia bahasa Indonesia dan bahasa Mandarin pada umumnya berfungsi untuk menerangkan kata yang lain, kata-kata yang diterangkan sebagian besar merupakan kata kerja dan kata sifat; (2) adverbia bahasa Indonesia bisa berupa reduplikasi, seperti: moga-moga, tiba-tiba, diam-diam, sungguh-sungguh dan sebagainya, sedangkan adverbial bahasa Mandarin tidak bisa reduplikasi; (3) adverbia Bahasa Indonesia bisa ditambahkan awalan dan akhiran, sedangkan adverbial bahasa Mandarin tidak bisa; dan (4) posisi adverbia Bahasa Mandarin dalam kalimat diletakkan di awal atau di tengah-tengah kalimat, sedangkan adverbial bahasa Indonesia bisa diletakkan di awal, tengah dan akhir kalimat.

\section{DAFTAR PUSTAKA}

Alisjahbana, S. T. (1986). Tata bahasa baru Bahasa Indonesia. Jakarta: Dian Rakyat.

Alisjahbana, S. T. (1986). Tata bahasa baru Bahasa Indonesia 2. Jakarta: Dian Rakyat.

Alwi, H., Soenjono, D., Hans, L., \& Anton, M. M. (2003). Tata Bahasa Baku Bahasa Indonesia. Jakarta: Balai Pustaka.

Arifin, E. Z. S., Amran, T. (2006). Cermat Berbahasa Indonesia. Akapress.

Dardjowidjojo, S. (1994). Beberapa aspek linguistik Bahasa Indonesia. Jakarta: Djambatan.

Pusat Pembinaan dan Pengembangan Bahasa. (2001). Pedoman umum Ejaan Bahasa Indonesia Yang Disempurnakan \& pedoman umum pembentukan istilah. Jakarta: Departemen Pendidikan Nasional Republik Indonesia.

Widjono, H. S. (2007). Bahasa Indonesia mata kuliah pengembangan kepribadian di perguruan tinggi. Jakarta: Grasindo.

陈华. 2004. 英汉句法结构比较研究[D]. 西安: 西安电子科技大学.

陈京苗. 2005. 汉泰语状语对比研究[D]. 云南: 云南师范大学.

方文惠. 1990. 英汉对比语言学[M]. 福建: 福建人民出版社.

房玉清. 1989. 使用汉语语法[M]. 北京: 北京语言学院出版社.

胡吉成. 2006. 现代汉语基础[M]. 北京: 北京大学出版社.

户福波. 2007. 对外汉语教学使用语法[M]. 北京: 北京语言大学出版社. 